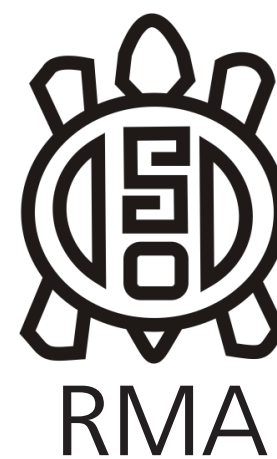

Arqueología

\section{El Holoceno Medio en valles fluviales del sudeste pampeano: ¿Escasez de sitios o de unidades portadoras? Una perspectiva geoarqueológica}

\author{
The Middle Holocene in the fluvial valleys in the southeastern pampas.
} Shortage of sites or carrier units? A geoarchaeological perspective

Cristian M. Favier Dubois*, Agustina Massigoge* y Pablo G. Messineo*

*INCUAPA-CONICET (Instituto de Investigaciones Arqueológicas y Paleontológicas del Cuaternario Pampeano). Facultad de Ciencias Sociales, Universidad Nacional del Centro de la Provincia de Buenos Aires, Argentina. E-mail: cfavier3@gmail.com, amassigo@soc. unicen.edu.ar, pmessine@soc.unicen.edu.ar

\begin{abstract}
Resumen
En este trabajo se presenta el estudio estratigráfico y cronológico de siete sitios arqueológicos localizados en las cuencas de los arroyos Cortaderas, Cristiano Muerto y Tapalqué (provincia de Buenos Aires, Argentina). El objetivo es evaluar si la ausencia y/o baja representación de unidades estratigráficas del Holoceno medio en estos cursos de bajo orden está condicionando la señal arqueológica en el sudeste pampeano. Los resultados indican que los depósitos correspondientes a este período resultan escasos y que, con frecuencia, existen discordancias erosivas entre las unidades datadas en el Holoceno tardío y aquellas correspondientes al Pleistoceno tardío u Holoceno temprano sobre las que apoyan. Este hecho también se observa en sitios localizados en otros cursos fluviales de bajo orden del sudeste pampeano. En consecuencia, la baja señal arqueológica del Holoceno medio en muchos valles puede deberse, al menos en parte, a este sesgo estratigráfico. Adicionalmente, los suelos/paleosuelos desarrollados en estas secuencias de planicie aluvial concentraron la evidencia cultural, lo cual genera una imagen de pulsos de ocupación humana y de hiatos arqueológicos que podría considerarse principalmente un resultado de la dinámica fluvial. Tal panorama estratigráfico en los cursos de bajo orden no sólo es válido para la región analizada sino que posee implicaciones para secuencias fluviales de numerosos valles en Argentina.
\end{abstract}

Palabras clave: Holoceno medio; valles fluviales; geoarqueología; hiatos arqueológicos; sudeste pampeano

\begin{abstract}
In this paper, the study of the stratigraphy and chronology of seven archaeological sites located in the streams Cortaderas, Cristiano Muerto and Tapalqué (province of Buenos Aires, Argentina) is presented. The aim of this study is to evaluate if the absence and/or low representation of the geological deposits corresponding to the Middle Holocene in these low-order streams is conditioning the archaeological signal in the southeastern pampas. Our results show that deposits corresponding to this time period are scarce and that erosional uncorformities between Late Holocene and Late Pleistocene or Early Holocene units are common. Besides, this situation is observed in sites located in other low-order streams in the southeastern pampas. Thus, the low archaeological signal for the Middle Holocene in many fluvial valleys could be the result, at least in part, of this stratigraphic bias. Furthermore, the soils/ paleosoils developed in the fluvial sequences have condensed the cultural evidence. This generates an image of periods of more intense human occupation and archaeological hiatus that could be the result of the fluvial dynamics. This stratigraphic scenario in low-order streams is valid not only for the studied area but also has implications for the chronology and preservation of archaeological sites in fluvial sequences in many valleys in Argentina.
\end{abstract}

Keywords: Middle Holocene; fluvial valleys; geoarchaeology; archaeological hiatus; southeastern Pampas

La información arqueológica generada en el sudeste de la región pampeana (Buenos Aires, Argentina) por distintos grupos de investigación indica su ocupación por sociedades cazadoras-recolectoras desde fines del Pleistoceno (ca. 12.200 años AP; ca. 14.500 años cal AP) hasta momentos históricos (ver síntesis en Politis 2008). En la llanura Interserrana y en las sierras de Tandilia se registran las evidencias más tempranas de ocupación y se observa una continuidad en la señal arqueológica a lo largo del periodo mencionado (Martínez et al. 2015). A pesar de esta continuidad, la distribución de frecuencias de fechados radiocarbónicos muestra fluctuaciones temporales importantes en su intensidad, algunas de las cuales han sido interpretadas en términos de cambios en las dinámicas poblacionales (Barrientos 2001; Barrientos y Pérez 2002, 2005; Martínez 2002; Martínez et al. 2015).

En relación con lo anterior, un problema discutido en la 
arqueología del sudeste pampeano ha sido la escasez de sitios en el Holoceno medio (ca. 6500-3500 años $\mathrm{AP}^{1}$; ca. 7370-3730 años cal AP) en comparación con el Holoceno temprano y el tardío (Barrientos y Masse 2014; Barrientos y Pérez 2005; Martínez et al. 2015). Distintos factores fueron propuestos para explicar esta baja representación arqueológica, incluyendo la ocurrencia de procesos de emigración o extinción local de poblaciones (Barrientos 2001; Barrientos y Pérez 2005), una disminución en la densidad poblacional (Politis 1986), un aumento de la movilidad residencial de las poblaciones cazadoras-recolectoras con la consecuente disminución en la visibilidad arqueológica (Martínez 1999) y sesgos científicos y tafonómicos (Favier Dubois 2006; Martínez et al. 2015). El importante aumento de sitios arqueológicos del sudeste pampeano datados en el Holoceno medio en los últimos años (e.g. Álvarez et al. 2013; Bayón et al. 2010, 2012; Bonomo y León 2010; Massigoge 2011a; Mazzanti et al. 2013, 2015; Messineo et al. 2014; Politis et al. 2014) ha hecho perder fuerza a la hipótesis de disrupción poblacional durante este lapso e invita a considerar en mayor profundidad algunos factores geológicos que podrían estar provocando sesgos en la representación arqueológica de este periodo.

Un primer acercamiento a este problema fue presentado por Favier Dubois (2006) sobre la base de un estudio geoarqueológico realizado en el río Quequén Grande. Dicho autor propuso que el bajo número de sitios asignados al Holoceno medio podría responder a que los depósitos de esta edad corresponden con frecuencia a bañados y lagunas someras, ambientes poco propicios para la ocupación humana. Esta misma situación fue planteada por Madrid et al. (2002) para el río Quequén Salado, lo que estaría señalando que este problema podría ser común en los cursos de elevado orden (colectores principales) de esta región.

\footnotetext{
${ }^{1}$ En este trabajo se decidió emplear la subdivisión temporal propuesta por Berón y Politis (1997), que ubica al Holoceno medio entre 6500 y 3500 años AP, ya que esta periodificación ha sido utilizada ampliamente en la región y en las propuestas originales referidas a una disminución de la señal arqueológica durante el mencionado intervalo.
}

El presente trabajo tiene como objetivo evaluar otro aspecto geomorfológico que podría estar condicionando la señal arqueológica del Holoceno medio en el sudeste pampeano: la ausencia o baja representación de unidades estratigráficas de esa cronología en las cuencas pequeñas, representadas por cursos de bajo orden. Para alcanzar este objetivo, se realizó el estudio de la estratigrafía y cronología de sitios arqueológicos localizados en las cuencas de los arroyos Cortaderas, Cristiano Muerto y Tapalqué (Figura 1). Complementariamente, sobre la base de información publicada, se analizaron sitios arqueológicos localizados en otros cursos de bajo orden del sudeste pampeano (arroyos Nutria Mansa y Claromecó, Figura 1).

\section{Cuencas fluviales, área de estudio y marco geológico- estratigráfico}

Las cuencas fluviales se inician con cursos colectores de bajo orden, rango que va aumentando a medida que se suman tributarios al sistema. Un curso sin afluentes es de orden 1, al unirse a otro del mismo orden éste se hace de orden 2, dos cursos de orden 2 hacen uno de orden 3 y así sucesivamente (Waters 1992: 116). Las cuencas pequeñas (generalmente arroyos) poseen pocos tributarios, y éstos son de bajo orden, alcanzando el curso principal un orden $\leq 3$. Las cuencas mayores reciben tributarios que alimentan a colectores principales, de orden $\geq 4$, que constituyen los ríos y valles de mayor desarrollo (Beeton y Mandel 2011).

Los sitios analizados en este trabajo se ubican en cuencas fluviales pequeñas del sudeste de la región pampeana, mayormente en la llanura Interserrana, localizada entre los cordones serranos de Tandilia y Ventania (Figura 1). Allí se desarrollan cursos permanentes de variada longitud y con predominio de vertiente atlántica. Se trata de ríos y arroyos autóctonos que se alimentan principalmente de la infiltración subterránea, poseen mediana sinuosidad y se hallan encajonados a expensas de la excavación de sus propios cauces, exponiendo depósitos antiguos que afloran en sus barrancas. Los sectores de interfluvio

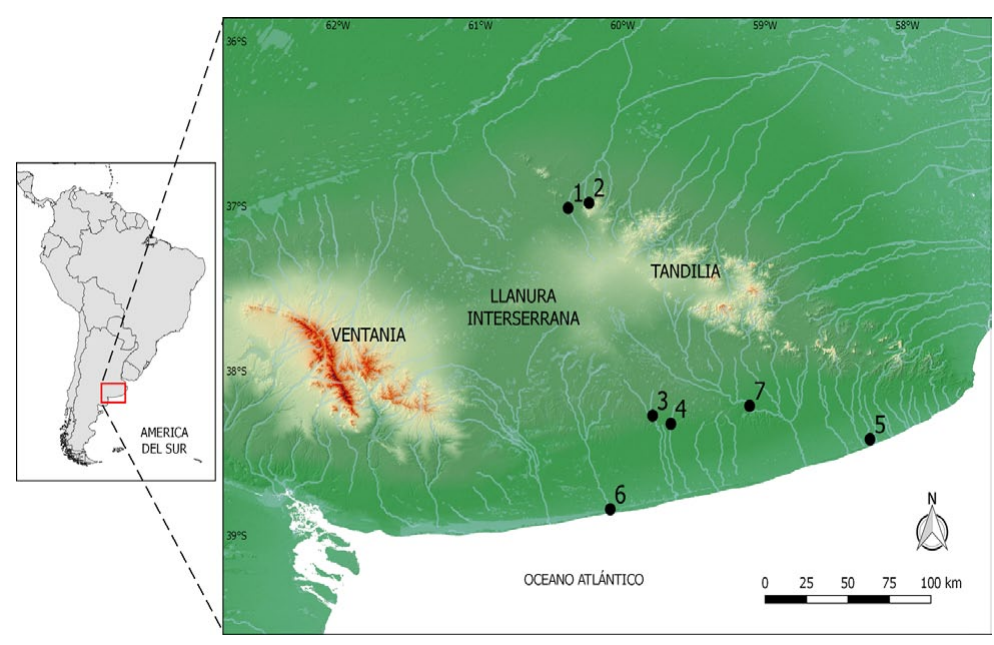

Figura 1. Localización en el sudeste pampeano de los cursos fluviales y sitios arqueológicos mencionados en el texto: 1. arroyo Tapalqué (sitios Campo Laborde y Empalme Querandíes 1), 2. arroyo San Jacinto (sitio El Puente), 3. arroyo Cristiano Chico (localidad arqueológica Las Brusquillas), 4. arroyo Cortaderas (sitio Cortaderas), 5. arroyo Nutria Mansa (sitio Nutria Mansa 1), 6. arroyo Claromecó (sitio Claromecó 1), 7. río Quequén Grande (sitio Paso Otero 4).

Figure 1. Map of the southeastern pampas showing the fluvial valleys and archaeological sites mentioned in the text: 1. Tapalqué stream (Campo Laborde and Empalme Querandies 1 sites), 2. San Jacinto stream (EI Puente site), 3. Cristiano Chico stream (Las Brusquillas locality), 4. Cortaderas stream (Cortaderas site), 5. Nutria Mansa stream (Nutria Mansa 1 site), 6. Claromecó stream (Claromecó 1 site), 7. Quequén Grande river (Paso Otero 4 site). 
corresponden a sedimentos loéssicos (Formación La Postrera, Fidalgo et al. 1973), sobre los que se desarrollan suelos fértiles (Molisoles) con buena expresión de horizontes. El río Quequén Grande es el mayor exponente fluvial de esta región, donde la descarga del escurrimiento subterráneo influye en el modelado de los cauces y en la configuración de las redes de drenaje (Kruse y Laurencena 2005). En la actualidad la región posee un clima húmedosubhúmedo, mesotérmico, con valores de precipitación media anual de $800 \mathrm{~mm}$ y de temperatura media anual de unos $14^{\circ} \mathrm{C}$. La vegetación natural corresponde a praderas herbáceas pero éstas se hallan intensamente modificadas por la agricultura intensiva y la ganadería (Soriano et al. 1992).

El conocimiento de la estratigrafía fluvial pampeana se ha basado en el estudio de secuencias de importantes ríos de la región (elevado orden) como el Luján y el Salado en la Pampa Ondulada y Deprimida, respectivamente (Ameghino 1889; Fidalgo et al. 1973, entre otros), o como el Quequén Grande en la Ilanura Interserrana (Zárate et al. 2000). Estas secuencias registran depósitos fluviales, fluvio-lacustres y, en menor medida, eólicos, así como paleosuelos, con cronologías que corresponden al Pleistoceno tardío y a diferentes momentos del Holoceno. La base de estas secuencias presenta sedimentos aluviales compuestos por arenas muy finas y limos arcillosos color verdoso, con abundantes restos de mamíferos extinguidos y nódulos de carbonato de calcio, correspondientes a lo que Ameghino (1889) designara como Lujanense en base a sus estudios en el río Luján. Los suprayacen depósitos fluvio-lacustres arcillolimosos, color gris blanquecino hasta oscuro, con una importante presencia de diatomeas, que Ameghino (1889) y Frenguelli (1950) denominaron Platense. Con posterioridad, en base a estudios realizados en el curso inferior del río Salado, Fidalgo et al. (1973, 1975) reúnen estos depósitos bajo el nombre de Formación Luján, diferenciando las unidades litoestratigráficas previamente reconocidas como miembros. El Lujanense pasa entonces a ser el Miembro Guerrero y el Platense el Miembro Río Salado de la Formación Luján. Las cronologías obtenidas a partir de numerosas dataciones radiocarbónicas ubican temporalmente al primero en el Pleistoceno tardío y al segundo en el Holoceno temprano y medio (ver síntesis en Zárate 2005). Fidalgo et al. (1973) mencionan asimismo la presencia de dos geosoles (unidades pedoestratigráficas) en esta secuencia, uno es el Suelo Puesto Callejón Viejo que se desarrolla sobre el Miembro Guerrero y el otro el Suelo Puesto Berrondo en el tope del Miembro Río Salado. Sobre este último suelo se desarrollan depósitos correspondientes al Holoceno tardío en los valles fluviales, cuyo estudio debe ser aún profundizado por su importancia arqueológica. Estos depósitos suelen ser referidos como sedimentos eólicos de la Formación La Postrera (Fidalgo et al. 1973) pero con frecuencia corresponden a sedimentos aluviales arenolimosos (Favier Dubois 2006; Fucks et al. 2007; Lanzellotti 2008) o a combinaciones de ambos (e.g., Prieto et al. 2004; Zárate et al. 2000, entre otros).

Si bien este esquema estratigráfico es válido a escala regional, no se observan representadas de la misma manera las unidades lito y pedoestratigráficas de referencia a lo largo de los valles pampeanos donde se ubican los sitios arqueológicos. Los cambios en los procesos de sedimentación y erosión fluvial a escala local introducen variabilidad depositacional, haciendo importante utilizar una metodología geoarqueológica (Waters 2000) para comprender la expresión de estos procesos en cada lugar y abordar su estudio en función de las escalas y preguntas de interés arqueológico. En relación con este problema, dos interrogantes principales que orientaron el presente trabajo fueron cómo se hallaban representados y qué características poseían los depósitos fluviales correspondientes al Holoceno medio en las áreas de investigación arqueológica involucradas; poniéndose de esta manera el foco en las unidades portadoras antes que en los propios materiales culturales.

\section{Metodología}

Con el objetivo de evaluar la baja señal del registro arqueológico correspondiente al Holoceno medio desde un abordaje geoarqueológico, se presentan en este trabajo las secuencias de siete sitios arqueológicos localizados en tres cuencas fluviales pequeñas del sudeste de la región pampeana. Se trata de las cuencas de los arroyos Cortaderas, Cristiano Muerto y Tapalqué. Las dos primeras son de vertiente atlántica (Nros. 3 y 4 en Figura 1), mientras que la del arroyo Tapalqué y su afluente el arroyo San Jacinto drena hacia la vertiente nororiental del sistema serrano de Tandilia (Nros. 1 y 2 en Figura 1). Los sitios ubicados en las márgenes de estos arroyos cuentan con edades radiocarbónicas que permiten evaluar la cronología de las unidades estratigráficas que los componen.

Se realizó un análisis de la estratigrafía a escala puntual y local (loci arqueológicos y áreas adyacentes a los mismos) de acuerdo con la metodología propuesta por Butzer (1982). Luego la estratigrafía se comparó con el esquema de referencia regional a fin de contextualizarla y evaluar sus particularidades en cada localidad, caracterizando las unidades y los ambientes representados a lo largo de la columna. Para la descripción de los perfiles se utilizó una perspectiva pedoestratigráfica, además de la litoestratigráfica, ya que permite una calibración más adecuada de la representación temporal de las secuencias en estudio y una mejor caracterización de los procesos postdepositacionales involucrados (Holliday et al. 1993). Los análisis texturales y de materia orgánica fueron realizados en el Laboratorio de Análisis Sedimentológicos de la Facultad de Ciencias Exactas y Naturales, Universidad Nacional de La Pampa (Santa Rosa). Las dataciones radiocarbónicas sobre materia orgánica en estos sitios 
se obtuvieron por el método convencional (Laboratorio de Tritio y Radiocarbono, LATYR, La Plata), mientras que las efectuadas sobre hueso y carbón se obtuvieron por la técnica de AMS (Arizona AMS Facility y Lawrence Livermore National Laboratory).

\section{Cuenca del arroyo Cortaderas}

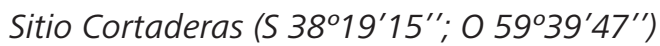

Este sitio se sitúa sobre la margen izquierda del arroyo homónimo. Fue excavado por primera vez a comienzos de la década de 1980, pero su estudio se vio interrumpido (Politis et al. 1983). En el año 2004, se retomaron las investigaciones bajo la dirección de uno de los autores (AM). En ambas etapas de trabajo se recuperó una asociación similar de materiales arqueológicos, constituida por abundantes restos faunísticos y artefactos líticos y escasos tiestos cerámicos y fragmentos de pigmento mineral. El análisis faunístico indicó que en el sitio se procesaron y consumieron distintos recursos animales, principalmente guanaco (Lama guanicoe), mientras que el estudio del material lítico mostró gran parte de las actividades de la secuencia de reducción lítica, en especial las tareas finales de manufactura de los instrumentos (Massigoge 2007; Massigoge y Pal 2011).

En la secuencia estratigráfica del sitio se reconocen tres unidades litoestratigráficas principales y dos unidades pedoestratigráficas (Figura 2). En la parte superior, se observa un depósito heterogéneo constituido por sedimentos clásticos finos y gruesos, de origen aluvialcoluvial (Unidad I; en adelante UI), coronado por un suelo de desarrollo reciente (perfil A-C-2C-3C). Este depósito se habría originado en tiempos históricos, posiblemente por procesos de inundación a gran escala (Massigoge 2007) cuyos efectos se amplifican por las actividades agrícolas. Por debajo de esta unidad, y en contacto claramente discordante, se observa un paleosuelo palustre de carácter cumúlico, de color negro y con gran contenido de materia orgánica (horizonte 4Ab1cum, Figura 2) desarrollado en sedimentos limoarcillosos (UII) de origen fluvio-lacustre vinculados a la antigua planicie aluvial. Esta unidad contiene gran parte de los materiales arqueológicos, los cuales se distribuyen de modo continuo sin observarse hiatos que permitan identificar diferentes momentos de ocupación humana. Un fragmento óseo de guanaco, con huellas de corte, fechado en $2270 \pm 190$ años AP permite asignar esta unidad al Holoceno tardío (Massigoge 2007). Por último, en la base de la secuencia, se identifican sedimentos aluviales arenolimosos, color verdoso a castaño claro, asignables al Miembro Guerrero de la Formación Luján (UIII). El contacto entre esta unidad y la Ull se presenta como ondulado y abrupto, aunque puede observarse levemente transicional en algunos sectores.

\section{Cuenca del arroyo Cristiano Muerto, arroyo Cristiano Chico}

Localidad arqueológica Las Brusquillas (S 38¹6'; O $\left.59^{\circ} 47^{\prime}\right)$

Esta localidad se halla ubicada en el arroyo Cristiano Chico, afluente del Cristiano Muerto. Desde el año 2005, en que dieron inicio las investigaciones, se han detectado cuatro sitios en estratigrafía, uno en depósitos eólicos de

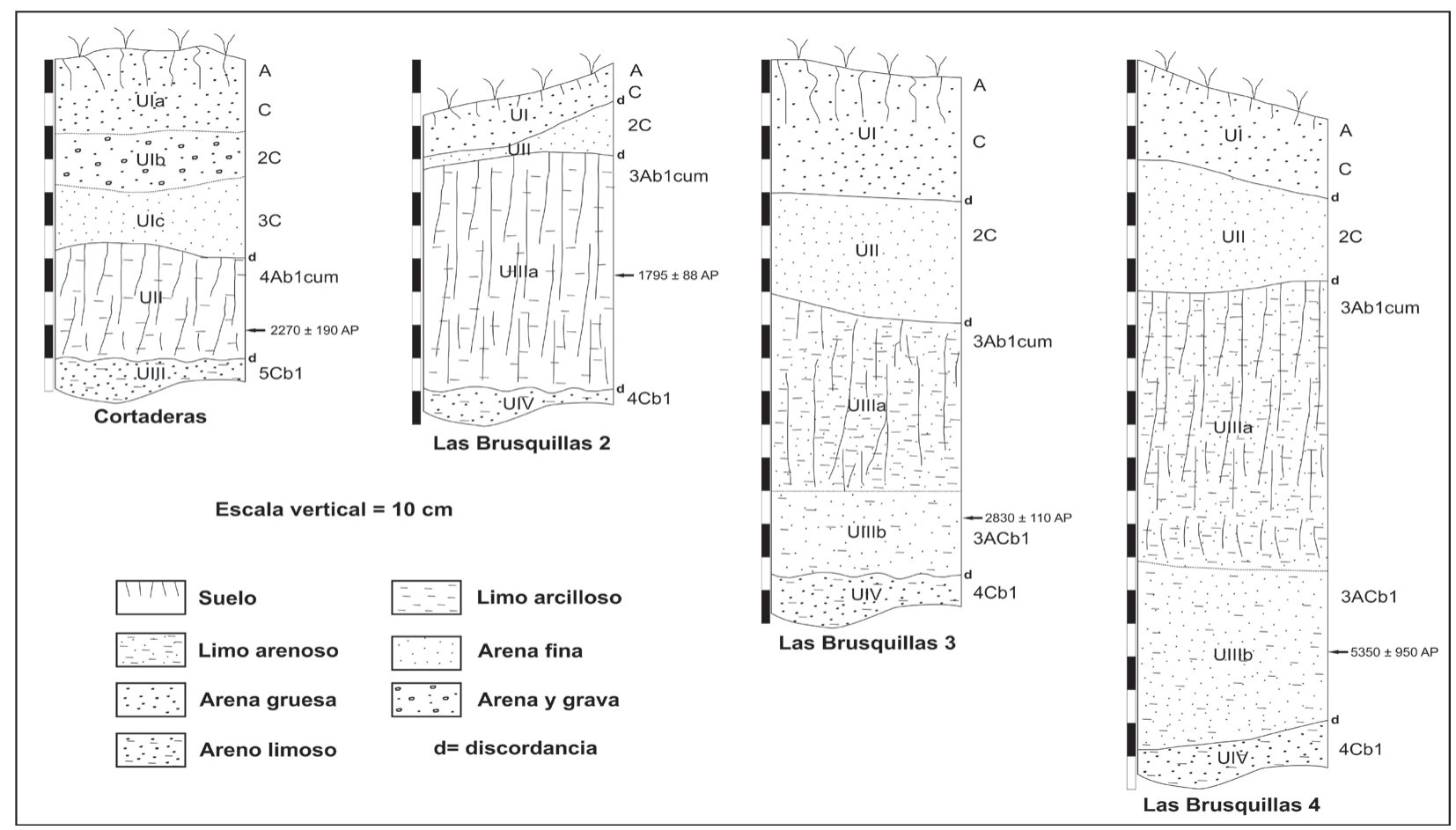

Figura 2. Perfiles estratigráficos de los sitios Cortaderas, Las Brusquillas 2, Las Brusquillas 3 y Las Brusquillas 4.

Figure 2. Stratigraphic sections from Cortaderas, Las Brusquillas 2, Las Brusquillas 3, and Las Brusquillas 4. 
interfluvio (Las Brusquillas 1; Massigoge 2012) y tres sobre la margen derecha del arroyo, en depósitos de origen fluvio-lacustre (Las Brusquillas 2, 3 y 4; Massigoge 2011a, 2011b; Massigoge y Pal 2011). En estos tres últimos se reconoció una secuencia estratigráfica similar, integrada por cuatro unidades litoestratigráficas principales y dos pedoestratigráficas (Figura 2). En la porción superior de la secuencia se identifica un depósito arenoso (UI), de probable origen aluvial-coluvial, sobre el cual se ha desarrollado el suelo actual (perfil A-C). Por debajo, y en discordancia erosiva, se observa un depósito también arenoso aunque de menor granulometría (UII), de origen fluvial. La unidad subyacente es un paleosuelo palustre de carácter cumúlico color negro (horizonte 3Ab1 cum, Figura 2) desarrollado en sedimentos limosos con proporción variable de arena y arcilla, de origen fluvio-lacustre (UIII). Esta unidad es semejante a la UII del sitio Cortaderas y, de la misma manera, es la que contiene el material arqueológico en los tres sitios de la localidad Las Brusquillas. Cambios en la coloración y diferencias menores en la granulometría dentro de la UIII permiten diferenciar dos subunidades con contactos transicionales entre sí, aunque estas subunidades no están representadas por igual en todos los sitios (Figura 2). Por último, en la base de la secuencia estratigráfica, y en contacto ondulado y abrupto con la UIII, se observa un depósito sedimentario arenolimoso de color verdoso a castaño claro (UIV), asignable al Miembro Guerrero de la Formación Luján.

En el sitio Las Brusquillas 2 se recuperó un gran número de restos faunísticos (principalmente de guanaco y venado de las pampas-Ozotoceros bezoarticus-), junto a escasos artefactos líticos y fragmentos cerámicos. Un fechado radiocarbónico realizado sobre un fragmento óseo de venado de las pampas con alteración térmica procedente de la parte media de la UIII arrojó una edad de $1795 \pm$ 88 años AP. El estudio tafonómico reveló que una parte importante de los restos faunísticos fue incorporada al depósito por procesos naturales, tales como la muerte natural de animales in situ o el transporte de sus carcasas por el agua. Asimismo, otros materiales fueron depositados durante las ocupaciones de cazadoresrecolectores en las que se produjo la explotación de guanacos y otros recursos animales (Massigoge 2011b).

Por su parte, en el sitio Las Brusquillas 3, ubicado a unos $60 \mathrm{~m}$ aguas arriba del sitio anterior, se recuperaron abundantes restos faunísticos y artefactos líticos y un reducido número de fragmentos de pigmento mineral (Massigoge et al. 2011). Un fechado radiocarbónico obtenido sobre un fragmento óseo de guanaco con huellas de corte recuperado en la parte inferior de la UIII dio una edad de $2830 \pm 110$ años AP (Rodríguez 2014). Durante las ocupaciones humanas representadas en este sitio se realizaron diversas actividades, incluyendo la manufactura, mantenimiento y utilización de instrumentos líticos y el procesamiento y consumo de distintas especies de animales, principalmente guanaco (Massigoge et al. 2011; Rodríguez 2014).

Por último, el sitio Las Brusquillas 4 se encuentra ubicado entre los dos sitios anteriores. Debido a que por el momento sólo se ha excavado un sondeo ( 1 x $1 \mathrm{~m})$, el conocimiento de este sitio es limitado. Los materiales arqueológicos, consistentes en abundantes restos

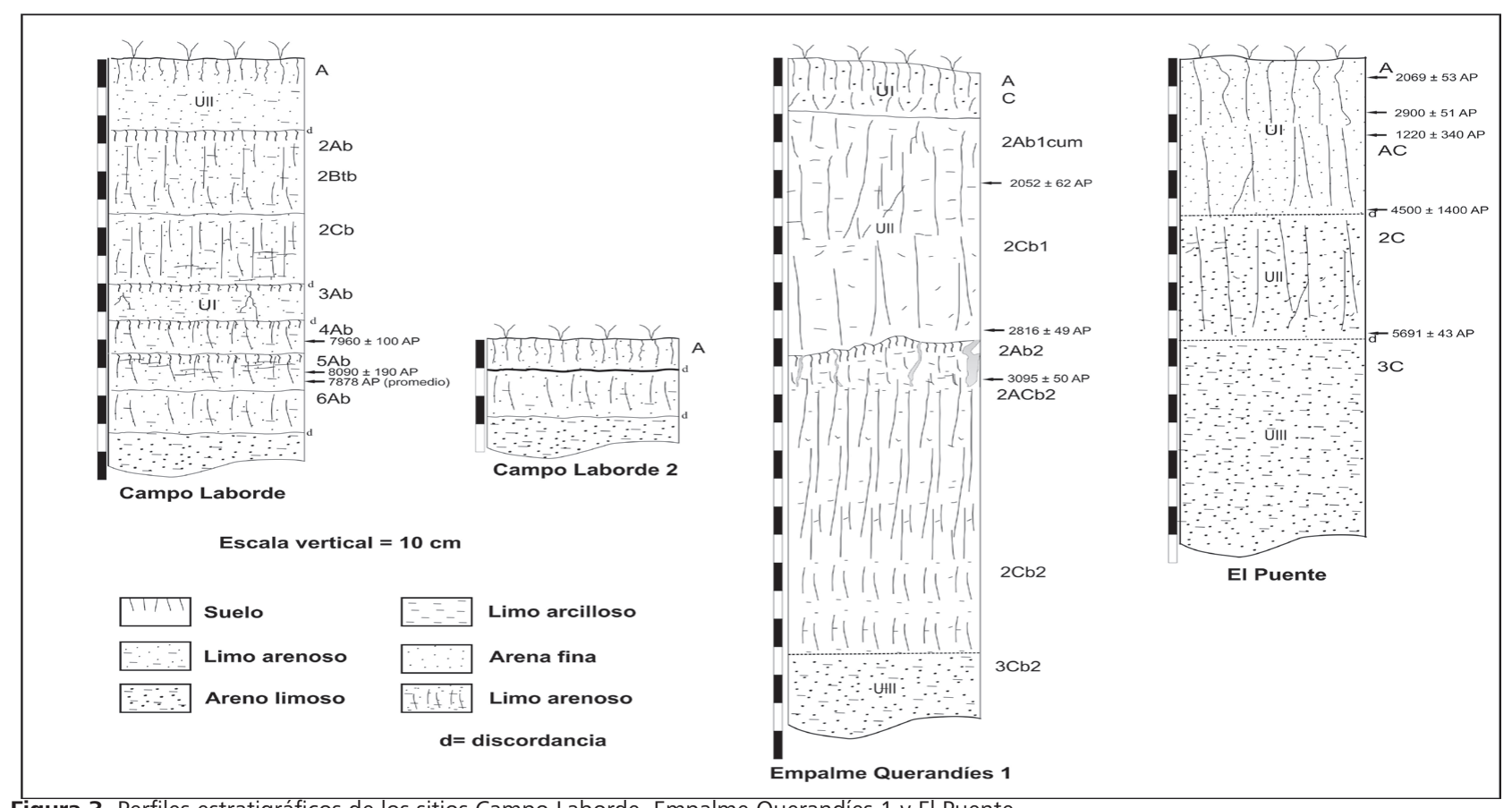

Figura 3. Perfiles estratigráficos de los sitios Campo Laborde, Empalme Querandíes 1 y El Puente.

Figure 3. Stratigraphic sections from Campo Laborde, Empalme Querandies 1, and El Puente. 
faunísticos y artefactos líticos, se hallaban en la base de la UIII (Massigoge 2011a). De esta unidad procede un hueso de guanaco fechado en $5350 \pm 950$ años AP (AA87929), el cual presenta claras evidencias de fractura antrópica. Si bien esta edad radiocarbónica debe ser tomada con precaución debido a la magnitud de su error estándar, permite plantear de modo preliminar que la depositación de la UIII, en algunos sectores del valle pudo iniciarse en el Holoceno medio.

\section{Arroyo Tapalqué/San Jacinto}

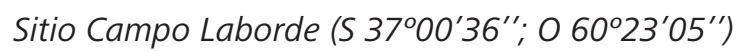

Este sitio arqueológico se encuentra sobre la margen izquierda de un curso tributario sin nombre que desemboca en el arroyo Tapalqué; fue excavado entre 2001 y 2003, bajo la dirección de uno de los autores (PGM) y del Dr. Gustavo Politis. En este sitio se recuperaron abundantes restos óseos de megamamíferos extinguidos, principalmente Megatherium americanum, asociados a fauna autóctona (Lama sp., Dolichotis patagonum, Lagostomus maximus, armadillos, etc.) y más de un centenar de artefactos líticos (Politis y Messineo 2008). Los análisis efectuados permiten inferir que en Campo Laborde se llevó a cabo la caza y el procesamiento inicial de un megaterio en el borde de lo que habría sido un antiguo pantano. El estudio de los materiales líticos muestra que en el sitio se realizaron las etapas finales de la manufactura de instrumentos y la reactivación de los mismos (Messineo 2012).

En la secuencia estratigráfica del sitio, Gentile (2008) identificó dos unidades litoestratigráficas (UI y UII): la superior, integrada por sedimentos limoarenosos y arenas muy finas limosas de color castaño a castaño negruzco correspondientes a los sedimentos eólicos asignados a la Formación La Postrera (UII) y la inferior, por los sedimentos fluviales arenolimosos, de color castaño verdoso, correspondientes al Miembro Guerrero (UI Sección Inferior) y fluvio-lacustres de color gris blanquecino asignable al Miembro Río Salado (UI Sección Superior), ambos de la Formación Luján. Asimismo, Douglas Frink (2005, en Messineo 2008) reconoció seis unidades pedoestratigráficas (en la Figura 3 se respeta la nomenclatura original asignada a los horizontes en este sitio).

En el tope de la secuencia se registra un depósito limoso de origen eólico en el cual se desarrolla el suelo actual (A). Por debajo, y en discordancia erosiva, se observa un depósito limoarenoso de probable origen aluvial sobre el cual se desarrolló un suelo (2Ab-2Btb-2Cb). El horizonte $2 \mathrm{Cb}$ presenta una estructura laminar con presencia de carbonato pedogenético. Por debajo de esta unidad, y en contacto claramente discordante, se reconoce el paleosuelo $3 \mathrm{Ab}$ representado por un sedimento gris ceniza, granulometría limo y la presencia de canalículos de color negro y carbonato de calcio en su interior. El horizonte 4Ab (infrayacente a la unidad anterior) se halla representado por un suelo desarrollado sobre sedimentos limoarenosos, color negro con manchas grises y sin presencia de carbonato de calcio. Una datación de materia orgánica de este paleosuelo dio una edad de $7960 \pm 100$ años AP. La unidad sedimentaria subyacente es un paquete pedogenizado (horizontes $5 A b$ y $6 A b)$ fluvio-lacustre vinculado con un ámbito de escasa energía de una planicie aluvial o paleopantano en la base del Miembro Río Salado de la Formación Luján (UI Sección Superior). Los materiales arqueológicos se concentran en este paquete y las dataciones efectuadas sobre diferentes huesos de Megatherium americanum ubican cronológicamente al contexto arqueológico en el Holoceno temprano (edad promediada de 7878 años AP para dicho componente). Asimismo, una datación sobre materia orgánica del paleopantano dio una edad de $8090 \pm 190$ años AP (Messineo y Politis 2009). Por último, en la base de la secuencia, se hallan expuestos los sedimentos aluviales areno-limosos, de color castaño verdoso, correspondientes al Miembro Guerrero de la Formación Luján (UI Sección Inferior).

Durante el 2010 se excavaron $4 \mathrm{~m}^{2}$ en el sitio denominado Campo Laborde sector 2, localizado sobre la margen derecha del curso tributario, a la misma altura que Campo Laborde. En este sitio se recuperaron restos óseos de Macrauchenia patachonica y escasos huesos dérmicos de un megamamífero indeterminado en la misma unidad estratigráfica descripta anteriormente (paleopantano en la base del Miembro Río Salado). Sin embargo, por encima de esta unidad, y separado por una discordancia de erosión, se identificó el horizonte A del suelo actual (Figura 3). Dicha discordancia erosionó parte de los depósitos del Holoceno temprano y la totalidad de los del Holoceno medio. Hasta el momento no se han obtenido dataciones por ${ }^{14} \mathrm{C}$ sobre los restos óseos de los megamamíferos recuperados en este sitio debido a la ausencia de colágeno.

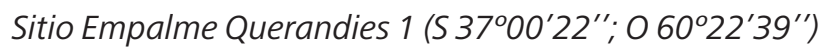
Se localiza sobre la margen izquierda del arroyo Tapalqué. Este sitio fue excavado entre 2010 y 2012, bajo la dirección de uno de los autores (PGM) y de la Dra. María C. Álvarez. Se recuperó una gran cantidad de restos de diversas especies animales, materiales líticos, fragmentos cerámicos, pigmentos minerales, fragmentos de caracoles marinos, una cuenta de valva, cáscaras de huevo e instrumentos óseos, entre otros hallazgos. Asimismo, se registraron dos concentraciones óseas de elementos de guanaco localizadas a diferentes profundidades, una de las cuales presentaba artefactos líticos asociados (Colantonio et al. 2016; Messineo et al. 2013). Parte de las ocupaciones del sitio Empalme Querandíes 1 estarían vinculadas con loci de actividades múltiples de campamentos base. Entre dichas actividades se destaca el procesamiento de diversos animales, la producción y uso de una amplia gama de artefactos líticos manufacturados 
por talla y por picado, la confección de instrumentos óseos, el uso de pigmentos minerales y la utilización de recipientes cerámicos.

La información estratigráfica indica que el material arqueológico se encuentra incluido en depósitos de origen fluvial en los que se reconocen tres unidades litoestratigráficas y tres pedoestratigráficas (Figura 3). En el tope de la secuencia se registra un depósito arenolimoso (UI), sobre el que se ha desarrollado un perfil de suelo $(A-C)$. El límite inferior de esta unidad es abrupto en varios sectores del perfil y apoya en discordancia sobre la unidad infrayacente, hecho posiblemente relacionado con la acción conjunta de eventos de inundación (erosión) y la acción de animales de hábitos fosoriales. A continuación le sigue la UII, un depósito limoso en el que se diferencian dos paleosuelos (Figura 3). El primero se inicia con el horizonte 2Ab1 que es de tipo cumúlico, color castaño oscuro. Una datación sobre un radiocúbito de guanaco con una fractura antrópica obtenido en este horizonte proporcionó una edad de $2052 \pm 62$ años AP. Por debajo se desarrolla el horizonte $2 \mathrm{Cb} 1$, castaño claro y con límite inferior abrupto. Una datación sobre una tibia de guanaco utilizada como soporte de un instrumento óseo dio una edad de $2816 \pm 49$ años AP. Por debajo se registra el segundo paleosuelo, que comienza con el horizonte 2Ab2 de color castaño; allí una datación sobre un metatarso de guanaco con huellas de corte arrojó una edad de $3095 \pm 50$ años AP. Luego se registran los horizontes $2 \mathrm{ACb} 2$ y $2 \mathrm{Cb} 2$, este último con límite inferior abrupto. En la base de la secuencia se observa la UIII, un depósito fluvial arenolimoso de color castaño verdoso y aspecto masivo asignable al Miembro Guerrero de la Formación Luján (Figura 3) que constituye el horizonte 3Cb2 del paleosuelo inferior.

Sitio El Puente (S 36 $58^{\prime} 44^{\prime \prime} ;$ o 60¹4'17")

El sitio El Puente se halla localizado sobre la margen izquierda del arroyo San Jacinto, en un valle intraserrano correspondiente al núcleo central de las Sierras Bayas. Este arroyo constituye el curso tributario más importante de la cuenca superior del arroyo Tapalqué. Este sitio fue excavado entre 2009 y 2011 bajo la dirección de uno de los autores (PGM) y del Dr. Cristian Kaufmann. Se recuperó una gran cantidad de elementos culturales, entre los que se destacan materiales líticos sobre diversas rocas, pigmentos minerales, escasos fragmentos de cerámica, artefactos elaborados sobre hueso y algunos ítems de origen europeo (e.g., metal, gres y nácar). Asociados con estos restos post-hispánicos se encontraron huesos correspondientes a diversas especies autóctonas y de fauna introducida (e.g., vaca y caballo), mientras que en los niveles inferiores se hallaron elementos óseos de guanaco y de un megamamífero indeterminado (Messineo et al. 2014).

Los materiales arqueológicos se encuentran incluidos en depósitos fluviales donde pueden diferenciarse tres unidades litoestratigráficas y una pedoestratigráfica que se les sobreimpone (Figura 3). Esta se halla constituida por un suelo que se desarrolla en la parte superior de la columna, de perfil A-AC-2C-3C. Los horizontes A y $A C$ poseen textura limoarenosa y se encuentran muy bioturbados. Es destacable la concentración de material arqueológico hacia la base del horizonte A, que tendría que ver con la intensa actividad de las lombrices que favoreció procesos de bioselección de materiales (ver Messineo et al. 2014). Ambos horizontes conforman la UI donde se registran algunos pequeños rodados y cuyo límite inferior es abrupto. Por debajo se desarrolla la UII que constituye el horizonte $2 \mathrm{C}$ del suelo, caracterizada como una unidad castaño clara, arenolimosa, masiva, en la que se observan moteados de carbonato de calcio a causa de la dinámica pedológica (lixiviación) y algunas manchas de materia orgánica vehiculizada por las raíces desde los niveles superiores. Esta unidad apoya en

Figura 4. Sucesión estratigráfica acortada frecuente en los cursos de bajo orden y en cuencas fluviales pequeñas del sudeste pampeano. A) arroyo Cristiano Chico, localidad Las Brusquillas; B) arroyo Tapalqué, próximo a Empalme Querandíes 1.

Figure 4. Shortened stratigraphic sequence frequently observed in low-order streams in the southeastern pampas. A) Cristiano Chico stream, Las Brusquillas locality; B) Tapalqué stream, close to the site Empalme Querandies 1.

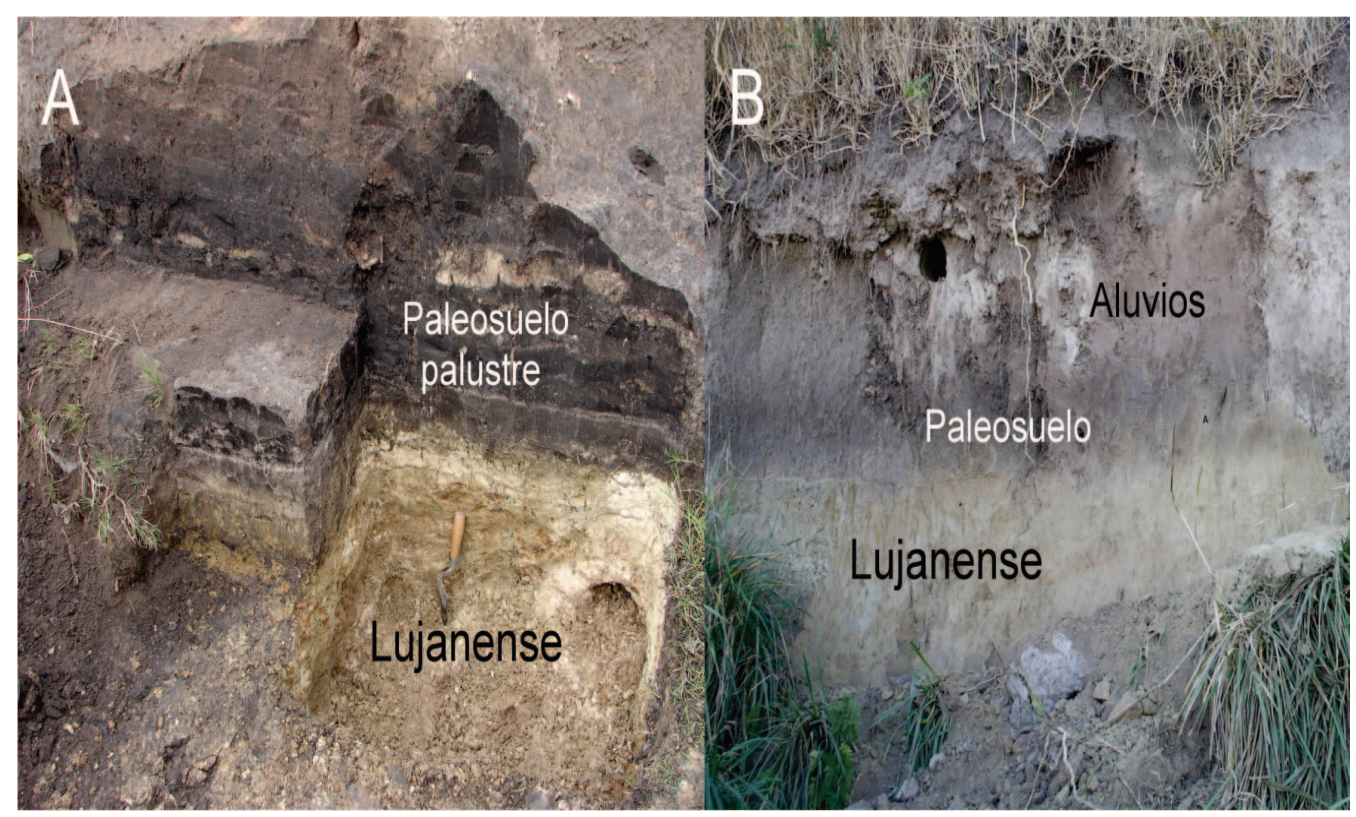


discordancia sobre la UIII u horizonte 3 C que se desarrolla en la base de la secuencia. Allí desaparecen los moteados de carbonato o son muy raros y la consistencia es mayor, constituyendo los típicos sedimentos arenolimosos del Miembro Guerrero de la Formación Luján. El contacto entre los horizontes $2 \mathrm{C}$ y $3 \mathrm{C}$ es discordante y representa el límite entre un Lujanense retrabajado (2C) y otro más típico, algo más claro y compacto (3C).

El material arqueológico se ubica desde el horizonte $A$ del suelo hasta la primera parte de la unidad castaño clara, que corresponde al horizonte 2C. Para este sitio se obtuvieron cuatro fechados sobre huesos de guanaco: dos de las muestras procedentes del horizonte $A$ y asociadas a fauna introducida, brindaron edades de $2069 \pm 53$ años AP y $2900 \pm 51$ años AP, una procedente del horizonte AC dio una edad de $1220 \pm 340$ años AP y otra recuperada en el límite entre los horizontes AC y 2C fue fechada en 4500 \pm 1400 años AP. Las dos últimas edades radiocarbónicas deben ser tomadas con precaución debido al amplio error estándar en las mediciones. Asimismo, se obtuvo una datación sobre un fragmento de carbón procedente de la base del horizonte 2C la cual dio una edad de 5691 \pm 34 años AP.

\section{Discusión}

La evidencia arqueológica del uso de los ambientes fluviales se halla modelada por los mismos procesos que dan forma a la secuencia estratigráfica fluvial, de esta forma los eventos de depositación, erosión y estabilidad son los responsables de preservar, organizar y fragmentar el registro de actividades humanas (Waters 2000). Tales procesos actúan de manera distinta en los diferentes cursos que se desarrollan a lo largo de una cuenca así como entre diferentes cuencas, haciendo que el registro sedimentario del Holoceno no se vea representado de manera uniforme en los valles (Bettis y Mandel 2002). La posición del curso en el sistema de drenaje resulta relevante dado que es la que establece el potencial para la preservación estratigráfica (Beeton y Mandel 2011; Bettis y Mandel 2002; Carver y Beeton 2014). En los sitios analizados del sudeste pampeano, ubicados en cursos de orden 2 y 3, las evidencias arqueológicas del Holoceno medio son escasas. Esta situación puede ser interpretada erróneamente como un "vacío ocupacional" o una disminución en la densidad poblacional a nivel regional. Sin embargo, el estudio geoarqueológico aquí presentado muestra que en estos cursos también se hallan casi ausentes las unidades fluvio-lacustres de esa cronología, entre ellas, los depósitos blanquecinos ricos en diatomeas usualmente asignables al Miembro Río Salado de la Formación de Luján. La evidencia arqueológica en los cursos de bajo orden se concentra entonces en depósitos y horizontes de suelo pertenecientes al Holoceno tardío (Favier Dubois 2015). Asimismo, es frecuente observar en estos cursos que las unidades correspondientes a este último intervalo apoyan sobre aquellas del
Pleistoceno tardío (i.e., sitios Cortaderas, Las Brusquillas 2 y 3, Empalme Querandíes 1, Campo Laborde sector 2) u ocasionalmente del Holoceno temprano (i.e., sitio Campo Laborde) indicando un hiato. En la Figura 4A se observa la pequeña barranca del arroyo Cristiano Chico, localidad Las Brusquillas, donde el depósito fluvio-lacustre pedogenizado del Holoceno tardío (paleosuelo palustre) apoya en discordancia sobre sedimentos asignados al Miembro Guerrero de la Formación Luján. La Figura 4B ilustra una situación discordante similar (el paleosuelo y los aluvios corresponden al Holoceno tardío) en un perfil natural muy próximo al sitio Empalme Querandíes 1.

Este hiato estratigráfico no solo se observa en las localidades analizadas sino en sitios de otras cuencas menores de la llanura Interserrana, como los arroyos Nutria Mansa (sitio Nutria Mansa 1, Favier Dubois y Bonomo 2008) y Claromecó (sitio Claromecó 1, Bonomo et al. 2008), donde tampoco se registran depósitos del Holoceno temprano/medio (Miembro Río Salado) y las unidades del Holoceno tardío que contienen la evidencia arqueológica apoyan en discontinuidad sobre el Miembro Guerrero (Tabla 1). Sin embargo, hay sectores en las cuencas menores donde se han preservado unidades y evidencia arqueológica del Holoceno medio. El fechado en el sitio El Puente (arroyo San Jacinto) de ca. 5700 años AP sobre carbón parece indicar que hubo materiales arqueológicos en esa secuencia y fueron luego erosionados, preservándose algunos en un depósito formado por sedimentos retrabajados del Miembro Guerrero (Messineo et al. 2014). Asimismo, en el sitio Las Brusquillas 4 (arroyo Cristiano Chico) se obtuvo una datación de ca. 5300 años AP sobre material óseo de origen cultural, en un depósito fluviolacustre que apoya sobre el Miembro Guerrero en ese locus (Tabla 1). Ello sugiere que una prospección sistemática, geoarqueológicamente orientada, podría ayudar a localizar contextos discretos de preservación correspondientes al Holoceno medio en cursos de bajo orden.

Una explicación para la escasez de depósitos del Holoceno medio en los valles fluviales del sudeste pampeano es el hecho de que los cursos de bajo orden representan el área de captación, transporte y mayor poder erosivo en la cuenca de drenaje, con menor potencial para albergar sedimentos que los cursos de elevado orden (Favier Dubois 2015) que se vinculan a los sectores de mayor desarrollo del valle. Sesgos estratigráficos similares para el Holoceno temprano y medio han sido estudiados en detalle en ríos de las grandes planicies norteamericanas (e.g., Bettis y Mandel 2002; Beeton y Mandel 2011; Carver y Beeton 2014). A manera de ejemplo y en forma similar a lo que ocurre en los valles del sudeste pampeano, en cuencas como la del río Pawnee (Kansas), los cursos de orden 2 y 3 se caracterizan por el transporte de sedimentos y la erosión entre ca. 10.500 y 4000 años $\mathrm{AP}$, mientras que durante el Holoceno tardío son sectores de almacenamiento de aluvios que suelen apoyar sobre 


\begin{tabular}{|c|c|c|c|c|c|}
\hline Curso & Sitio & Unidad estratigráfica & Edad C14 & Material datado & Referencias bibliográficas \\
\hline \multirow[t]{32}{*}{ Río Quequén Grande } & \multirow[t]{5}{*}{ Paso Otero 1} & La Postrera/Paleosuelo & $2974 \pm 48^{*}$ & Materia orgánica & \multirow[t]{5}{*}{ Johnson et al. 2012} \\
\hline & & Mb. Río Salado/Puesto Berrondo & $3050 \pm 42$ & Hueso (Lama guanicoe) & \\
\hline & & Mb. Río Salado/Puesto Berrondo & $4750 \pm 60^{*}$ & Materia orgánica & \\
\hline & & Mb. Río Salado/Puesto Berrondo & $4855 \pm 110^{*}$ & Materia orgánica & \\
\hline & & Mb. Guerrero/Paleosuelo & $9950 \pm 50^{*}$ & Materia orgánica & \\
\hline & \multirow[t]{7}{*}{ Paso Otero 3} & La Postrera/Paleosuelo & $1571 \pm 60^{*}$ & Materia orgánica & \multirow[t]{7}{*}{ Johnson et al. 2012} \\
\hline & & La Postrera/Paleosuelo & $2061 \pm 70^{*}$ & Materia orgánica & \\
\hline & & La Postrera/Paleosuelo & $2137 \pm 70^{*}$ & Materia orgánica & \\
\hline & & La Postrera/Paleosuelo & $2460 \pm 70^{*}$ & Materia orgánica & \\
\hline & & Mb. Río Salado?/Paleosuelo & $3020 \pm 80$ & Materia orgánica & \\
\hline & & Mb. Río Salado?/Puesto Berrondo & $4756 \pm 60^{*}$ & Materia orgánica & \\
\hline & & Mb. Río Salado?/Puesto Berrondo & $4713 \pm 60^{*}$ & Materia orgánica & \\
\hline & \multirow[t]{11}{*}{ Paso Otero 4} & Mb. Río Salado/Puesto Berrondo & $2281 \pm 38^{*}$ & Materia orgánica & \multirow[t]{11}{*}{ Álvarez et al. 2013; Gutiérrez et al. 2010, 2011} \\
\hline & & Mb. Río Salado/Paleosuelo & $4561 \pm 41$ & Materia orgánica & \\
\hline & & Mb. Río Salado/Paleosuelo & $5559 \pm 43$ & Materia orgánica & \\
\hline & & Mb. Río Salado/Paleosuelo & $6739 \pm 48$ & Materia orgánica & \\
\hline & & Mb. Río Salado/Paleosuelo & $7729 \pm 48$ & Materia orgánica & \\
\hline & & Rasgo cultural (pozo) & $8075 \pm 66$ & Materia orgánica & \\
\hline & & Rasgo cultural (pozo) & $8556 \pm 65$ & Carbón & \\
\hline & & Rasgo cultural (pozo) & $8735 \pm 48$ & Materia orgánica & \\
\hline & & Rasgo cultural (pozo) & $8760 \pm 160$ & Materia orgánica & \\
\hline & & Mb. Río Salado/Paleosuelo & $8913 \pm 49$ & Materia orgánica & \\
\hline & & Mb. Guerrero/Puesto Callejón Viejo & $9912 \pm 53^{*}$ & Materia orgánica & \\
\hline & \multirow[t]{9}{*}{ Paso Otero 5} & Mb. Río Salado/Paleosuelo & $2490 \pm 70^{*}$ & Materia orgánica & \multirow[t]{9}{*}{ Johnson et al. 2012} \\
\hline & & Mb. Río Salado/Paleosuelo & $4210 \pm 70^{*}$ & Materia orgánica & \\
\hline & & Mb. Río Salado/Paleosuelo & $6629 \pm 130^{*}$ & Materia orgánica & \\
\hline & & Mb. Río Salado/Paleosuelo & $7794 \pm 70^{*}$ & Materia orgánica & \\
\hline & & Mb. Río Salado/Paleosuelo & $8793 \pm 90^{*}$ & Materia orgánica & \\
\hline & & Mb. Guerrero/Puesto Callejón Viejo & $9399 \pm 120$ & Materia orgánica & \\
\hline & & Mb. Guerrero/Puesto Callejón Viejo & $9560 \pm 50$ & Hueso (Megatherium americanum) & \\
\hline & & Mb. Guerrero/Puesto Callejón Viejo & $10440 \pm 100$ & Hueso (Megatherium americanum) & \\
\hline & & Mb. Guerrero/Puesto Callejón Viejo & $10190 \pm 120$ & Hueso (Megamamífero indet) & \\
\hline \multirow[t]{11}{*}{ Río Quequén Salado } & \multirow[t]{4}{*}{ Quequén Salado 1} & \multirow{2}{*}{$\begin{array}{l}\text { La Postrera/Paleosuelo } \\
\text { La Postrera/Paleosuelo }\end{array}$} & $360 \pm 40$ & Hueso (Lama guanicoe) & \multirow[t]{6}{*}{ Madrid et al. 2002; Steffan et al. 2010} \\
\hline & & & $790 \pm 40$ & Hueso (Lama guanicoe) & \\
\hline & & La Postrera/Paleosuelo & $940 \pm 40$ & Hueso (Lama guanicoe) & \\
\hline & & La Postrera/Paleosuelo & $960 \pm 40$ & Hueso (Lama guanicoe) & \\
\hline & Quequén Salado 2 & Sin datos & $1720 \pm 40$ & Hueso (Lama guanicoe) & \\
\hline & Quequén Salado 4 & Sin datos & $1240 \pm 40$ & Hueso (Lama guanicoe) & \\
\hline & \multirow[t]{5}{*}{ La Represa Antigua } & Sin datos & $2110 \pm 40$ & Hueso (Lama guanicoe) & \multirow[t]{5}{*}{ Hoguin y March 2007-2008; March et al. 2011} \\
\hline & & Sin datos & $2900 \pm 40$ & Hueso (Lama guanicoe) & \\
\hline & & Sin datos & $3050 \pm 40$ & Hueso (Lama guanicoe) & \\
\hline & & Sin datos & $3180 \pm 40$ & Hueso (Lama guanicoe) & \\
\hline & & Sin datos & $3430 \pm 40$ & Hueso (Lama guanicoe) & \\
\hline \multirow[t]{3}{*}{$A^{\circ}$ Nutria Mansa } & \multirow[t]{3}{*}{ Nutria Mansa 1} & Mb. Río Salado?/Paleosuelo palustre & $2705 \pm 66$ & Diente (Lama guanicoe) & \multirow[t]{3}{*}{ Bonomo 2005; Favier Dubois y Bonomo 2008} \\
\hline & & Mb. Río Salado?/Paleosuelo palustre & $2920 \pm 110$ & Diente (Lama guanicoe) & \\
\hline & & Mb. Río Salado?/Paleosuelo palustre & $3080 \pm 110$ & Diente (Lama guanicoe) & \\
\hline$A^{0}$ Cortaderas & Cortaderas & Paleosuelo palustre & $2270 \pm 190$ & Hueso (Lama guanicoe) & Massigoge 2007 \\
\hline \multirow[t]{3}{*}{$\mathrm{A}^{\circ}$ Cristiano Chico } & Las Brusquillas 2 & Paleosuelo palustre & $1795 \pm 88$ & Hueso (Ozotoceros bezoarticus) & Massigoge 2011a \\
\hline & Las Brusquillas 3 & Paleosuelo palustre & $2830 \pm 110$ & Hueso (Lama guanicoe) & Rodríguez 2014 \\
\hline & Las Brusquillas 4 & Paleosuelo palustre & $5350 \pm 950^{* *}$ & Hueso (Lama guanicoe) & Este trabajo \\
\hline
\end{tabular}

Tabla 1. Cronologías obtenidas en cuencas mayores (ríos) y menores (arroyos) del sudeste pampeano en las que se han excavado y datado sitios arqueológicos en depósitos fluviales.

* Dataciones de materia orgánica en depósitos arqueológicamente estériles

** Fecha con amplio rango de error

*** El material datado en 5700 años AP en este sitio se hallaba en una unidad particular, referible a un Lujanense redepositado (Messineo et al. 2014).

Table 1. Chronologies obtained in high-order and low-order streams in the southeastern pampas where archaeological sites in fluvial deposits have been excavated.

* Dates from organic matter from sterile units.

** Date with a large standard error.

*** The material dated at ca. 5700 years PB was recovered in a geological units described as re-deposited Lujanense (Messineo et al. 2014).

depósitos fluviales del Pleistoceno o directamente sobre sustrato rocoso (Bettis y Mandel 2002: 144-145). De esta forma, el conocimiento de los patrones de evolución del paisaje fluvial y de los sesgos en la preservación de unidades estratigráficas puede contribuir a la evaluación del potencial cronológico de las secuencias representadas en los cursos de una cuenca en forma previa a su estudio arqueológico. Así, este tipo de sesgo geológico se convierte en algo predecible que ayuda a explicar hiatos observados en el registro cultural (Beeton y Mandel 2011; Carver y Beeton 2014).

En relación con esta dinámica, varios de los casos analizados muestran que los procesos erosivos que 
eliminaron los depósitos del Holoceno medio afectaron asimismo aquellos correspondientes al temprano y a la transición Pleistoceno-Holoceno (con excepción del sitio Campo Laborde). Ello también disminuye las posibilidades de encontrar evidencias de ocupaciones para esa etapa en estos valles. Asimismo, se debe destacar que la ausencia de depósitos del Holoceno medio reduce la potencia estratigráfica (secuencias acortadas) y aumenta el impacto de la materia orgánica derivada de la pedogénesis del Holoceno tardío sobre las unidades lito o pedoestratigráficas del Pleistoceno tardío-Holoceno temprano que pudieron preservarse. De esta manera, sería más probable que existan procesos de rejuvenecimiento de edades en estos contextos, a causa de la contaminación a partir de componentes del humus (principalmente ácidos fúlvicos) derivados del desarrollo de suelos en la parte superior de los perfiles. El colágeno óseo es sensible a estos contaminantes que no son fáciles de eliminar durante el pretratamiento de las muestras (Brock et al. 2013; Wang et al. 2010).

En este sentido, es interesante notar que, tanto en el sitio Campo Laborde (arroyo Tapalqué) como en La Moderna (arroyo Azul), donde se obtuvieron edades sobre restos de megafauna entre $c a .8000$ y 7000 años AP (Politis y Gutiérrez 1998; Politis y Messineo 2008), los materiales arqueológicos se encuentran en unidades que poseen abundante materia orgánica procedente de procesos de pedogénesis ulteriores. De esta manera, el contexto pedoestratigráfico de estos sitios en los que se evidencia supervivencia de la megafauna en el Holoceno temprano estaría generando procesos potencialmente

\begin{tabular}{|c|c|c|c|c|}
\hline $\begin{array}{c}\text { Contexto } \\
\text { sedimentario }\end{array}$ & Sitio & Material datado & Edad C14 & $\begin{array}{c}\text { Referencias } \\
\text { bibliográficas }\end{array}$ \\
\hline \multirow[t]{19}{*}{ Eólico } & \multirow[t]{6}{*}{ Arroyo Seco 2} & Hueso (Homo sapiens) & $4487 \pm 45$ & \multirow[t]{6}{*}{ Politis et al. 2014} \\
\hline & & Hueso (Homo sapiens) & $4793 \pm 69$ & \\
\hline & & Hueso (Lama guanicoe) & $5793 \pm 64$ & \\
\hline & & Hueso (Homo sapiens) & $6300 \pm 70$ & \\
\hline & & Diente (Canidae) & $6495 \pm 65$ & \\
\hline & & Hueso (Homo sapiens) & $6560 \pm 60$ & \\
\hline & \multirow[t]{2}{*}{ Fortín Necochea } & Hueso (Lama guanicoe) & $3630 \pm 60$ & \multirow[t]{2}{*}{ Crivelli et al. 1987-1988 } \\
\hline & & Hueso (Lama guanicoe) & $6010 \pm 400$ & \\
\hline & \multirow[t]{3}{*}{ Paso Mayor YIS1 } & Hueso (Lama guanicoe) & $3820 \pm 47$ & \multirow[t]{3}{*}{ Bayón et al. 2010} \\
\hline & & Hueso (Lama guanicoe) & $4046 \pm 57$ & \\
\hline & & Hueso (Lama guanicoe) & $5877 \pm 63$ & \\
\hline & Arroyo del Moro & Hueso (Homo sapiens) & $6220 \pm 40$ & \multirow[t]{2}{*}{ Bonomo et al. 2013} \\
\hline & Necochea & Hueso (Homo sapiens) & $6220 \pm 40$ & \\
\hline & \multirow[t]{2}{*}{ Loma de los Morteros } & Hueso (Lama guanicoe) & $4269 \pm 59$ & \multirow[t]{3}{*}{ Stoessel 2015} \\
\hline & & Hueso (Homo sapiens) & $4454 \pm 60$ & \\
\hline & La Modesta & Hueso (Lama guanicoe) & $5641 \pm 66$ & \\
\hline & \multirow{3}{*}{$\begin{array}{c}\text { Cantera de Rodado } \\
\text { Villalonga }\end{array}$} & Hueso (Homo sapiens) & $4100 \pm 80$ & \multirow[t]{3}{*}{ Martínez et al. 2012} \\
\hline & & Hueso (Homo sapiens) & $4502 \pm 56$ & \\
\hline & & Hueso (Homo sapiens) & $4889 \pm 58$ & \\
\hline Laguna costera & Alfar & Hueso (Otaridae) & $5704 \pm 64$ & Bonomo y León 2010 \\
\hline \multirow[t]{5}{*}{ Fluvial } & El Puente & Hueso (Lama guanicoe) & $\begin{array}{l}4500 \\
1400\end{array}$ & \multirow[t]{2}{*}{ \pm Messineo et al. 2014} \\
\hline & & Carbón & $5691 \pm 34$ & \\
\hline & \multirow[t]{2}{*}{ Paso Otero 4} & Materia orgánica & $4561 \pm 41$ & \multirow[t]{2}{*}{ Gutiérrez et al. 2010} \\
\hline & & Materia orgánica & $5559 \pm 43$ & \\
\hline & Las Brusquillas 4 & Hueso (Lama guanicoe) & $5350 \pm 950$ & Este trabajo \\
\hline \multirow{2}{*}{$\begin{array}{l}\text { Cuevas, aleros, } \\
\text { ladera serrana }\end{array}$} & El Abra (Ventana) & Carbón & $6230 \pm 90$ & Castro 1983 \\
\hline & Alero El Mirador & Carbón & $5089 \pm 40$ & Mazzanti et al. 2013 \\
\hline
\end{tabular}

Tabla 2. Fechados de sitios arqueológicos correspondientes al Holoceno medio (6500-3500 años AP) localizados en diferentes contextos sedimentarios del sudeste pampeano.

Table 2. Radiocarbon dates from archaeological sites corresponding to the Middle Holocene (6500-3500 years AP) located in different sedimentary environments in the southeastern pampas. 
rejuvenecedores (ver también Toledo 2011; Toledo y Schewenninger 2014).

Para finalizar este panorama estratigráfico fluvial, en referencia a dos de los principales cursos del sudeste pampeano, los ríos Quequén Grande y Quequén Salado (Tabla 1), el cauce actual corta depósitos del antiguo valle que suelen representar facies centrales de lagunas someras correspondientes al Holoceno temprano/medio (ver Madrid et al. 2002). En estos casos, la escasez de material cultural para ese largo intervalo estaría claramente relacionada con los ambientes saturados de agua predominantemente representados, poco propicios para las ocupaciones humanas (Madrid et al. 2002; Favier Dubois 2006 y 2015). Existe al momento un único sitio arqueológico con fechados del Holoceno medio en el río Quequén Grande, Paso Otero 4 (PO4). En este caso, las dataciones que dieron entre ca. 8900 y 4500 años AP fueron realizadas sobre materia orgánica de paleosuelos incipientes desarrollados en los mencionados sedimentos del Miembro Río Salado (Gutiérrez et al. 2010, 2011).

La escasez de sitios arqueológicos del Holoceno medio y su notable incremento para el Holoceno tardío se ha invocado como evidencia para proponer un importante incremento demográfico durante este último periodo en el sudeste pampeano (Martínez et al. 2015; Politis y Madrid 2001, entre otros). No obstante, la confiabilidad de los modelos paleodemográficos basados en información arqueológica depende en gran medida de la cantidad y calidad de los datos disponibles acerca de la preservación diferencial de unidades estratigráficas, tanto en lo espacial como en lo temporal (Bettis y Mandel 2002). Las cuencas fluviales poseen sus particulares sesgos por lo que la representación del registro del Holoceno medio en otros ambientes sedimentarios de la región permitirá una mejor evaluación de las hipótesis que postulan cambios demográficos. De hecho, el creciente número de dataciones que corresponden a este lapso para sitios emplazados en cuevas y aleros, médanos costeros y depósitos eólicos continentales (Tabla 2), han puesto en cuestionamiento la existencia de un vacío ocupacional entre 6000 y 5000 años AP. Las secuencias eólicas, por ejemplo, están manifestando un interesante potencial para obtener cronologías en el Holoceno medio a escala regional (Bayón et al. 2010; Massigoge et al. 2014; Politis et al. 2014, entre otros).

\section{Conclusiones}

Como se ilustra en este trabajo, uno de los principales factores que puede explicar la escasez de evidencia arqueológica para el Holoceno medio en las cuencas fluviales pequeñas es la baja representación de unidades estratigráficas de esa cronología que poseen los cursos de bajo orden. A este sesgo estratigráfico se suma un sesgo de carácter paleoambiental en los de elevado orden. En este sentido, los colectores principales registran unidades del Holoceno medio que se hallan vinculadas con ambientes lacustres y suelos hidromórficos poco aptos para la ocupación humana. Entonces la falta de unidades fluviales del Holoceno medio en los cursos menores y la escasez de unidades con potencial para contener evidencia antrópica en los cursos principales ayuda a explicar la escasa cantidad de sitios correspondientes a este intervalo en los valles del sudeste pampeano. En ambos contextos, los paleosuelos condensan la evidencia cultural que resulta mejor representada cuanto mayor haya sido la duración de los mismos como superficie estabilizada. Los depósitos fluvio-lacustres no representan comparativamente tanto tiempo y se ha visto que en muchos casos no se producen bajo condiciones favorables a la presencia humana. Ello concentra el material arqueológico de forma diferencial en determinadas unidades estratigráficas modelando su resolución y nuestra percepción acerca de los momentos y la intensidad de las ocupaciones en las cuencas fluviales a lo largo del tiempo.

Paralelamente, el desarrollo de suelos ricos en materia orgánica, particularmente durante el Holoceno tardío, ha repercutido sobre las unidades infrayacentes atravesadas por sus raíces. En el caso de secuencias donde no se han preservado unidades del Holoceno medio (i.e., cursos de bajo orden) la percolación de compuestos húmicos afectó particularmente depósitos y suelos del Pleistoceno tardíoHoloceno temprano constituyendo un contexto favorable para el rejuvenecimiento de edades radiocarbónicas en esas unidades.

La evidencia de ocupaciones humanas se ve afectada por procesos geológicos antes de convertirse en el registro arqueológico; éstos suelen ser diferentes en cada ambiente de sedimentación por lo que la integración de información estratigráfica y cronológica procedente de distintos contextos geoambientales permite obtener un mejor panorama sobre la continuidad o discontinuidad de las ocupaciones humanas en una región. Un panorama temporal más adecuado se está obteniendo en el sudeste pampeano a partir de una creciente cantidad de fechados en ambientes diferentes al fluvial.

Olavarría, octubre de 2016

\section{Agradecimientos}

Las investigaciones en los sitios bajo estudio fueron financiados por la ANPCyT (Proyectos PICT N² 2008-0415, $N^{\circ} 2010-1415$ y N²010-0235). Esta investigación forma parte de la Unidad Ejecutora INCUAPA-CONICET-UNICEN (Investigaciones Arqueológicas y Paleontológicas del Cuaternario Pampeano) dirigida por el Dr. G. Politis. Se agradece la contribución de los evaluadores anónimos en la mejora de este manuscrito. Las opiniones vertidas en el presente trabajo son de nuestra absoluta responsabilidad. 


\section{Referencias bibliográficas}

Álvarez, M. C., A. P. Alcaráz, M. A. Gutiérrez y G. Martínez. 2013. Análisis zooarqueológico del sitio Paso Otero 4 (Partido de Necochea, provincia de Buenos Aires, Argentina). Aportes a la discusión de modelos de subsistencia de la región pampeana. Intersecciones en Antropología 14: 383-398.

Ameghino, F. 1889. Contribución al conocimiento de los mamíferos fósiles de la República Argentina. Academia Nacional de Ciencias, Actas VI, pp. 1-1027, Córdoba.

Barrientos, G. 2001. Una aproximación bioarqueológica al estudio del poblamiento prehistórico tardío del Sudeste de la Región Pampeana. Intersecciones en Antropología 2: 3-18.

Barrientos, G., W. B. Masse. 2014. The archaeology of cosmic impact: Lessons from two mid-Holocene Argentine case studies. Journal of Archaeology Method and Theory 21 (1): 134-211.

Barrientos, G., S. I. Pérez. 2002. La dinámica del poblamiento humano del Sudeste de la Región Pampeana durante el Holoceno. Intersecciones en Antropología 3: 41-54.

Barrientos, G., S. I. Pérez. 2005. Was there a population replacement during the mid-Holocene in the southeastern Pampas of Argentina? Archaeological evidence and paleoecological basis. Quaternary International 132: 95-105.

Bayón, C., R. Pupio, R. Frontini, R. Vecchi y C. Scabuzzo. 2010. Localidad arqueológica Paso Mayor: nuevos estudios 40 años después. Intersecciones en Antropología 11: 115-128.

Bayón, C., R. Frontini y R. Vecchi. 2012. Middle Holocene settlements on coastal dunes, southwest Buenos Aires Province, Argentina. Quaternary International 256: 5461.

Beeton J. M., R. D. Mandel. 2011. Soils and LateQuaternary landscape evolution in the Cottonwood River Basin, East-Central Kansas: Implications for archaeological research. Geoarchaeology: An International Journal 26(5): 693-723.

Berón, M. A., G. G. Politis. 1997. Arqueología pampeana en la década de los '90. Estado de las investigaciones y perspectivas. En M. A. Berón y G. G. Politis (Eds.), Arqueología Pampeana en la Década de los '90, pp. 7-32, Museo de Historia Natural de San Rafael/INCUAPA, Facultad de Ciencias Sociales, Universidad Nacional del Centro de la Provincia de Buenos Aires, Olavarría.
Bettis III, E. A., R. D. Mandel 2002. The effects of temporal and spatial patterns of Holocene erosion and alluviation on the archaeological record of the Central and Eastern Great Plains, USA. Geoarchaeology: An International Journal 17(2): 141-154.

Bonomo, M. 2005. Costeando las llanuras. Arqueología del litoral marítimo pampeano. Colección Tesis Doctorales. Sociedad Argentina de Antropología, Buenos Aires.

Bonomo, M., D. C. León. 2010. Un contexto arqueológico en posición estratigráfica en los médanos litoral del sitio Alfar (Pdo. de Gral. Pueyrredón, Pcia. de Bs. As.). En M. Berón, L. Luna, M. Bonomo, C. Montalvo, C. Aranda y M. Carrera Aizpitarte (Eds.), Mamül Mapu: Pasado y Presente desde la Arqueología Pampeana, pp.29-45, Libros del Espinillo, Ayacucho.

Bonomo M., D. C. León, L. Turnes y E. Apolinaire. 2008. Nuevas investigaciones sobre la ocupación prehispánica de la costa pampeana, el sitio arqueológico Claromecó 1 (Partido de Tres Arroyos, provincia de Buenos Aires). Intersecciones en Antropología 9: 25-41.

Bonomo, M., C. Scabuzzo y C. León. 2013. Cronología y dieta en la costa atlántica pampeana, Argentina. Intersecciones en Antropología 14: 123-136.

Brock, F., V. Geoghegan, B. Thomas, K. Jurkschat y T. F. G. Higham. 2013. Analysis of bone "collagen" extraction products for radiocarbon dating. Radiocarbon, 55(2-3): 445-463.

Brown, A. G. 1997. Alluvial Geoarchaeology. Floodplain Archaeology and Environmental Change. Cambridge University Press, Cambridge.

Butzer, K. 1982. Archaeology as Human Ecology. Method and Theory for a Contextual Approach. Cambridge University Press, Cambridge.

Carver D. P., J. M. Beeton. 2014. Holocene landscape evolution and geoarchaeology of low-order streams in the Rio Grande basin, San Juan Mountains, Colorado, USA. Quaternary Research 82: 331-341.

Castro, A. 1983. Noticia preliminar sobre un yacimiento en la Sierra de la Ventana, Provincia de Buenos Aires. Relaciones de la Sociedad Argentina de Antropología XV: 91-107.

Crivelli Montero, E. A., M. J. Silveira, E. O. Eugenio, P. S. Escola, M. M. Fernández y N. V. Franco. 1987-1988. El sitio Fortín Necochea (Partido de General La Madrid, Provincia de Buenos Aires). Estado actual de los trabajos. Paleoetnológica 4: 39-53. 
Colantonio, M. J., N. Pal y P. G. Messineo. 2016. Análisis de las prácticas de producción y uso de los materiales líticos del sitio Empalme Querandíes 1 (cuenca superior del Arroyo Tapalqué, Región Pampeana). Arqueología 22 (2): 243-268.

Favier Dubois, C. M. 2006. Dinámica fluvial, paleoambientes y ocupaciones humanas en la localidad arqueológica Paso Otero, río Quequén Grande, Pcia. de Buenos Aires. Intersecciones en Antropología 7: 109-127.

Favier Dubois, C. M. 2015. Continuidades y discontinuidades: el sesgo arqueológico del Holoceno medio en los valles pampeanos (Argentina) desde una mirada geoarqueológica. En J. Rubin de Rubin, C. M. Favier Dubois y R. T. Da Silva (Eds.), Geoarqueología na America do Sul, Capítulo 3, pp. 91-108, PUC Goiás, Goiás.

Favier Dubois, C. M., M. Bonomo. 2008. Geoarqueología en el arroyo Nutria Mansa (Pdos. de General Alvarado y Lobería, Provincia de Buenos Aires). Comechingonia 11: 9-30.

Fidalgo, F., F. De Francesco y U. Colado. 1973. Geología Superficial de las Hojas Castelli, J.M. Cobo y Monasterio (Argentina). Relaciones del 6to. Congreso Geológico Argentino, pp. 103-138, Bahía Blanca.

Fidalgo F., F. De Francesco y R. Pascual. 1975. Geología superficial de la llanura Bonaerense. Geología de la Provincia de Buenos Aires, VI Congreso Geológico Argentino, Relatorio, pp. 103-138, Bahía Blanca.

Frenguelli, J. 1950. Rasgos generales de la morfología y la geología de la provincia de Buenos Aires. LEMIT, Serie 2 (33): 1-72. La Plata.

Fucks, E., R. Huarte, J. Carbonari y A. Figini. 2007. Geocronología, paleoambientes y paleosuelos holocenos en la región pampeana. Revista de la Asociación Geológica Argentina 62 (3): 425-433.

Gentile, R. O. 2008. Geología del Cenozoico superior en el sector del sitio arqueológico Campo Laborde (partido de Olavarría, provincia de Buenos Aires). Manuscrito en el Departamento de Arqueología, Facultad de Ciencias Sociales, Universidad Nacional del Centro de la Provincia de Buenos Aires. Olavarría.

Gutiérrez, M. A., G. Martínez, H. Luchsinger, M. C. Álvarez y M. P. Barros. 2010. Investigaciones arqueológicas y geoarqueológicas preliminares en el sitio Paso Otero 4 (partido de Necochea). En M. Berón, L. Luna, M. Bonomo, C. Montalvo, C. Aranda y M. Carrera Aizpitarte (Eds.), Mamül Mapu: Pasado y Presente de la Arqueología Pampeana, pp. 69-84, Libros del Espinillo, Ayacucho.

Gutiérrez, M., G. Martínez, H. Luchsinger, S. Grill, A. Zucol,
G. Hassan, M. P. Barros, C. A. Kaufmann y M. C. Álvarez. 2011. Paleoenvironments in the Paso Otero locality during late Pleistocene-Holocene (Pampean region, Argentina): an interdisciplinary approach. Quaternary International 245: 37-47.

Holliday, V. T., C. Reid Ferring y P. Goldberg. 1993. The scale of soil investigations in archaeology. En J. K. Stein y A. R. Linse (Eds.), Effects of Scale on Archaeological and Geoscientific Perspectives, Geological Society of America, Special Paper 238: 29-37.

Hoguin, R., R. March. 2007-2008. Una primera aproximación al análisis tipo-tecnológico de los artefactos líticos del sitio La Represa, curso inferior del Quequén Saldado (Pampa Húmeda, provincia de Buenos Aires). Arqueología 14: 103-136.

Johnson, E., V. T. Holliday, G. Martínez, M. A. Gutiérrez y G. G. Politis. 2012. Geochronology and landscape development along the middle Río Quequén Grande at the Paso Otero Locality, Pampa Interserrana, Argentina. Geoarchaeology: an International Journal 27: 300-323.

Kruse, E., P. Laurencena. 2005. Aguas superficiales. Relación con el régimen subterráneo y fenómenos de anegamiento. En R. de Barrio, R. O. Etcheverry, M. F. Caballé y E. Llambías (Eds.), Geología y Recursos Minerales de la Provincia de Buenos Aires. Relatorio del XVI Congreso Geológico Argentino, pp.313-326, La Plata.

Lanzellotti, S. L. 2008. A río revuelto... Geoarqueología, resolución e integridad del registro arqueológico en el río Quequén Grande (provincia de Buenos Aires). Intersecciones en Antropología 9: 43-57.

Madrid, P., G. Politis, R. March y M. Bonomo. 2002. Arqueología microrregional en el Sudeste de la Región Pampeana argentina: el Curso del río Quequén Salado. Relaciones de la Sociedad Argentina de Antropología XXVII: 327-355.

March R., C. Rodríguez Loredo, R. Hoguin, S. Foisset, D Joly y A. Lucquin. 2011. Primeros resultados de la excavación del sitio de cazadores recolectores de La Represa, Oriente, Partido de Coronel Dorrego, Provincia de Buenos Aires, Argentina. Arqueología Rosarina Hoy 3: 9-74.

Martínez, G. A. 1999. "Tecnología, subsistencia y asentamiento en el curso medio del Río Quequén Grande: Un enfoque arqueológico". Facultad de Ciencias Naturales y Museo, Universidad Nacional de La Plata, La Plata, Argentina. Tesis Doctoral no publicada.

Martínez, G. 2002. Organización y cambio en las estrategias tecnológicas: Un caso arqueológico e implicaciones comportamentales para la evolución de 
las sociedades cazadoras-recolectoras pampeanas. En G. Martínez y J. L. Lanata (Eds.), Perspectivas Integradoras entre Arqueología y Evolución. Teoría, Método y Casos de Aplicación, Serie Teórica 1, pp. 121-156, INCUAPA, Universidad Nacional de Centro de la Provincia de Buenos Aires, Olavarría.

Martínez, G. 2006. Arqueología del curso medio del río Quequén Grande: estado actual y aportes a la arqueología de la región pampeana. Relaciones de la Sociedad Argentina de Antropología XXXI: 249-275.

Martínez, G., G. Flensborg y P. D. Bayala. 2012. Primeras evidencias de restos óseos humanos en el curso inferior del río Colorado durante el Holoceno medio: sitio cantera de Rodados Villalonga (Pdo. de Patagones, Pcia. de Buenos Aires). Cazadores-Recolectores del Cono Sur, Revista de Arqueología 6: 101-113.

Martínez, G. A., D. L. Mazzanti, C. Quintana, A. Zucol, M. Colobig, G. Hassan, M. Brea y E. Passeggi. 2013. Geoarchaeological and Paleoenvironmental context of the human settlement in the Eastern Tandilia Range, Argentina. Quaternary International 299: 23-37.

Martínez G., L. Prates, G. Flensborg, L. Stoessel, A. P. Alcaráz y P. Bayala. 2015. Radiocarbon trends in the Pampean region (Argentina). Biases and demographic patterns during the final Late Pleistocene and Holocene. Quaternary International 356: 89-110.

Massigoge A. 2007. Procesos de formación del registro arqueológico en el sitio Cortaderas (Partido de San Cayetano, Provincia de Buenos Aires). Intersecciones en Antropología 8: 197-214.

Massigoge, A. 2011a. Nuevas evidencias arqueológicas del Holoceno medio y tardío del área Interserrana: Localidad Las Brusquillas (partido de San Cayetano, provincia de Buenos Aires). Resúmenes del VI Congreso de Arqueología de la Región Pampeana Argentina. Revista del Museo de La Plata. Arqueología 12 (86): 55. La Plata.

Massigoge, A. 2011b. Nuevas evidencias arqueológicas del Holoceno tardío en el Área Interserrana: el sitio Las Brusquillas 2 (Partido de San Cayetano, Provincia de Buenos Aires). Cazadores Recolectores del Cono Sur, Revista de Arqueología 5: 179-195.

Massigoge, A. 2012. Las Brusquillas 1 (partido de San Cayetano, provincia de Buenos Aires): un nuevo sitio del Holoceno tardío del área Interserrana de la región pampeana. Intersecciones en Antropología 13: 377-392.

Massigoge, A., N. Pal. 2011. Producción y uso de artefactos líticos en contextos cazadores-recolectores del Holoceno tardío del área Interserrana (Argentina): análisis integral de la diversidad tecno-morfológica y funcional. Revista Española de Antropología Americana 41 (1): 51-73.

Massigoge, A, R. F. Torino, P. G. Steffan, M. N. Rodríguez y D. Rafuse. 2011. Investigaciones arqueológicas en el sitio Las Brusquillas 3 (partido de San Cayetano, provincia de Buenos Aires). Resúmenes del VI Congreso de Arqueología de la Región Pampeana Argentina. Revista del Museo de La Plata. Arqueología 12 (86): 55-56. La Plata.

Massigoge, A., D. J. Rafuse, M. N. Rodríguez, J. M. Rodríguez, R. T. Torino, P. G. Steffan y C. M. Favier Dubois. 2014. Analyses of the faunal assemblage from the Las Toscas 5 site: a middle Holocene hunter-gatherer site from the southeastern Pampa Region (Argentina). Resúmenes del 12a International Conference of Archaeozoology, pp. 106-107. San Rafael.

Mazzanti, D. L., C. A. Quintana (Eds.). 2001. Cueva Tixi: Cazadores y Recolectores de las Sierras de Tandilia Oriental. 1 Geología, Paleontología y Zooarqueología. Publicación especial 1. Universidad Nacional de Mar del Plata, Mar del Plata.

Mazzanti, D. L., M. M. Colobig, A. F. Zucol, G. A. Martínez, J. Porto López, M. Brea, E. Passeggi, J. L. Soria, C. Quintana y V. Puente. 2010. Investigaciones arqueológicas en el Sitio 1 de la Localidad Lobería I. En M. Berón, L. Luna, M. Bonomo, C. Montalvo, C. Aranda y M. Carrera Aizpitarte (Eds.), Mamül Mapu: Pasado y Presente desde la Arqueología Pampeana, pp. 99-114, Editorial Libros del Espinillo, Ayacucho.

Mazzanti, D. L., G. Martínez, M. M. Colobig, A. Zucol, E. Passeggi, M. Brea, F. Bonnat, G. Hassan, J. L. Soria, J. A. Vera y C. A. Quintana. 2013. Avances en los estudios arqueológicos, geoarqueológicos y paleoambientales en las sierras orientales de Tandilia. Resultados preliminares de los sitios Alero El Mirador y Abrigo La Grieta. Revista del Museo de La Plata, Antropología 13: 59-66.

Mazzanti, D. L., G. A. Martínez y C. Quintana. 2015. Asentamientos del Holoceno medio en Tandilia oriental. Aportes para el conocimiento de la dinámica poblacional de la región pampeana, Argentina. Relaciones de la Sociedad Argentina de Antropología XL (1): 209-231.

Messineo P. G. 2011. Investigaciones arqueológicas en la cuenca superior del arroyo Tapalqué. Un modelo de ocupación humana para el centro de la subregión Pampa Húmeda durante el Holoceno tardío. Intersecciones en Antropología 12: 275-291.

Messineo, P. G. 2012. Lithic technology at Campo Laborde, an early-Holocene megamammal hunting site in the Pampean region (Argentina). En L. Miotti, M. Salemme, N. Flegenheimer y T. Goebel (Eds.), Southbound, Late Pleistocene Peopling of Latin America, 
Current Research in the Pleistocene, Special Edition, pp. 93-97, Center for the Study of the First Americans, Texas A\&M University, Texas.

Messineo, P. G., G. G. Politis. 2009. New radiocarbon dates from the Campo Laborde site (Pampean Region, Argentina) support the Holocene survival of giant ground sloth and glyptodonts. Current Research in the Pleistocene 26: 5-9.

Messineo P. G., M. C. Álvarez, C. M. Favier Dubois, P. Steffan y M. J. Colantonio. 2013. Estado de avance de las investigaciones arqueológicas en el sitio Empalme Querandíes 1 (centro de la subregión Pampa Húmeda, Provincia de Buenos Aires). Comechingonia 17: 123-148.

Messineo P. G., C. Kaufmann, P. Steffan, C. M. Favier Dubois y N. Pal 2014. Ocupaciones humanas en un valle intraserrano del sector Noroccidental de Tandilia: sitio El Puente (Partido de Olavarría, Buenos Aires). Relaciones de la Sociedad Argentina de Antropología XXXIX (2): 435-462.

Politis, G. G. 1986. Investigaciones arqueológicas en el Área Interserrana Bonaerense. Etnia 32: 7-52.

Politis, G. G. 2008. The Pampas and Campos of South America. En H. Silverman y W. H. Isbell (Eds.), Handbook of South American Archaeology, pp. 235-260, Springer, Nueva York.

Politis G. G., M. A. Gutiérrez 1998. Gliptodontes y cazadores-recolectores de la región pampeana (Argentina). Latin American Antiquity 9 (2): 111-134.

Politis, G. G., P. Madrid. 2001. Arqueología Pampeana: estado actual y perspectivas. En E. Berberian y A. Nielsen (Eds.), Historia Argentina Prehispánica, pp. 737-814, Córdoba.

Politis, G. G., P. G. Messineo. 2008. The Campo Laborde site: New evidence for the Holocene survival of Pleistocene megafauna in the Argentine Pampas. Quaternary International 191: 98-114.

Politis, G. G., P. Messineo, C. A. Kaufmann, M. P. Barros, M. C. Álvarez, V. Di Prado y R. Scalise. 2005. Persistencia ritual entre cazadores-recolectores de la llanura pampeana. En P. Kaulicke y T. Dillehay (Eds.), Encuentros: Identidad, Poder y Manejo de los Espacios Públicos, pp. 67-90, Boletín de Arqueología PUCP 9, Lima.

Politis, G. G., E. Tonni y F. Fidalgo. 1983. Cambios corológicos de algunos mamíferos en el Área Interserrana de la Provincia de Buenos Aires durante el Holoceno. Ameghiniana 20 (1-2): 72-80.

Politis, G. G., Gutiérrez, M., Scabuzzo, C. (Eds.). 2014.
Estado Actual de las Investigaciones en el Sitio Arroyo Seco 2 (Pdo. de Tres Arroyos, Pcia. de Buenos Aires, Argentina). Serie Monográfica del INCUAPA No. 5. FACSO-UNICEN, Olavarría.

Prieto, A. R., A. M. Blasi, C. G. De Francesco y C. Fernández. 2004. Environmental history since 11.000 14C yr BP of the northeastern Pampas, Argentina, from alluvial sequences of the Luján River. Quaternary Research 62: 146-161.

Rodríguez, M. N. 2014. El rol de los pequeños vertebrados en la subsistencia de las sociedades cazadoras-recolectoras del Holoceno tardío del área Interserrana: el caso del sitio Las Brusquillas 3 (partido de San Cayetano, provincia de Buenos Aires). En A. Castro Esnal, M. L. Funes, M. Grosso, N. Kuperszmit, A. Murgo y G. Romero (Eds.), Entre Pasados y Presentes IV. Estudios Contemporáneos en Ciencias Antropológicas, pp. 461-473, Asociación Amigos del Instituto Nacional de Antropología, E-book, Buenos Aires.

Soriano, A., R. J. C. León, O. E. Sala, R. S. Lavado, V. A. Deregibus, M. A. Cauhépé, O. A. Scaglia, C. A. Velázquez y J. Lencoff. 1992. Río de la Plata Grasslands. En R. T. Coupland (Ed.), Ecosystems of the World 8A. Natural Grasslands. Introduction and Western Hemisphere, pp. 367-413, Elsevier, Amsterdam.

Scheifler, N., P. G. Messineo y U. F. J. Pardiñas. 2015. Los pequeños vertebrados del sitio arqueológico Campo Laborde: procesos de incorporación y consideraciones paleoambientales. Archaeofauna: International Journal of Archaeozoology 24: 187-208.

Steffan, P. G., P. Madrid, G. Gómez y L. Mormeneo. 2010. Evaluación de la información paleoambiental y la dinámica de ocupación humana en el curso inferior del río Quequén Salado durante el holoceno tardío. En M. Berón, L. Luna, M. Bonomo, C. Montalvo, C. Aranda y M. Carrera Aizpitarte (Eds.), Mamül Mapu: Pasado y Presente desde la Arqueología Pampeana, pp. 215-226, Editorial Libros del Espinillo, Ayacucho.

Stoessel, L. 2015. Tendencias preliminares sobre el consumo de peces durante el Holoceno medio en el área de transición pampeano-patagónica oriental (Pcia. de Buenos Aires). Archaeofauna. International Journal of Archaeozoology 24: 103-117.

Toledo, M. J. 2011. El legado lujanense de Ameghino: revisión estratigráfica de los depósitos pleistocenosholocenos del valle del río Luján en su sección tipo. Registro paleoclimático en la pampa de los estadios OIS 4 al OIS 1. Revista de la Asociación Geológica Argentina 68 (1): $121-167$.

Toledo, M. J., y J. L. Schewenninger. 2014. Black Mats 
at the Pleistocene-Holocene transition in pampean valleys: implications for ${ }^{14} \mathrm{C}$ dating, geoarchaeology and chronology of megafauna extintions. Resúmenes del XIX Congreso Geológico Argentino, Córdoba.

Wang H., S. H. Ambrose, K. M. Hedman y T. E. Emerson. 2010. AMS 14C dating of human bones using sequential pyrolysis and combustion of collagen. Radiocarbon 52 (1): 157-163.

Waters M. R. 1992. Principles of Geoarchaeology: A North American perspective. University of Arizona Press, Tucson.

Waters, M. R. 2000. Alluvial stratigraphy and geoarchaeology in the American Southwest. Geoarchaeology: An International Journal 15 (6): 537557.
Waters M. R., D. D. Kuehn. 1996. The geoarchaeology of place: the effect of geological processes on the preservation and interpretation of the archaeological record. American Antiquity 61 (3): 483-497.

Zárate, M., R. A. Kemp, M. Espinosa y L. Ferrero. 2000. Pedosedimentary and palaeoenvironmental significance of a Holocene alluvial sequence in the southern Pampas, Argentina. The Holocene 10 (4): 481-488.

Zárate, M. 2005. El Cenozoico tardío continental de la Provincia de Buenos Aires. En R. de Barrio, R. O. Etcheverry, M. F. Caballé y E. Llambías (Eds.), Geología y Recursos Minerales de la Provincia de Buenos Aires. Relatorio del XVI Congreso Geológico Argentino, pp.139158, La Plata. 